\title{
A DIEZ AÑOS DEL GOLPE DE ESTADO: RUPTURA DE UN PROCESO NACIONAL POPULAR Y AFIANZAMIENTO DE LA DERECHA EN HONDURAS
}

\author{
TEN YEARS AFTER THE COUP D'ÉTAT: RUPTURE OF A POPULAR \\ NATIONAL PROCESS AND SECURITY OF THE RIGHT IN HONDURAS
}

Néstor Véliz Catalán

Recibido: 18/07/2019 - Aceptado: 16/10/2019

\begin{abstract}
Resumen
En este artículo se analizan las causales de la ruptura del proceso nacional popular liderado por Manuel Zelaya en junio de 2009. Se realiza una contextualización histórica de las fuerzas involucradas en ello, la derecha e izquierda y el modo en que las Fuerzas Armadas asumen el rol de "ordenadoras" de la nación y árbitros de la polarización en un escenario de expansión del chavismo en la región desde fines del siglo XX. También se presenta una interpretación del golpe como expresión de fuerzas y bloques políticos antagónicos, cuyo enfrentamiento fue reactualizado con el giro de Zelaya al campo de influencia del chavismo venezolano. Esta corriente político-ideológica dio lugar al "zelayismo" o una forma hondureña de populismo de izquierdas, que constituyó el "enemigo" a derrotar por parte de la derecha.
\end{abstract}

Palabras clave: afianzamiento, golpe de Estado, historia política, Honduras, ruptura.

\begin{abstract}
This article analyzes the causes of the rupture of the national pupil process led by Manuel Zelaya in June 2009. For this, in the first section, a historical contextualization of the forces involved in it, the right and left, to the addition of Chavismo, expanding in the region since the end of the 20th century. An interpretation of the coup is also presented as an expression of antagonistic forces and political blocs, whose confrontation was updated with the turn of Zelaya to the field of influence of Venezuelan Chavismo. This political-ideological current gave rise to "zelayism" or a Honduran form of left-wing populism, which constituted the "enemy" to defeat by the right.
\end{abstract}

Keywords: backing, coupd'état, Honduras; political history, rupture. 


\section{Introducción}

\section{Precisiones conceptuales y enfoque}

La hipótesis central que se sustenta en este artículo es que el actual fortalecimiento y afianzamiento de la derecha que se observa en la reelección de Juan Orlando Hernández en Honduras obedece a la revitalización de la derecha después del golpe que derribó a Manuel Zelaya Rosales el 28 de junio de 2009. Lo anterior fue indispensable para que el mandatario haya triunfado en las elecciones de 2017, lo cual fue preludiado por el desempeño de Roberto Michelletti Baín, sucesor interino de Zelaya, protagonista de la coyuntura golpista y Porfirio "Pepe" Lobo Sosa, antiguo presidente del Congreso.

Una de las orientaciones fundamentales de la propuesta es encontrar en el apartamiento de Zelaya una expresión de la histórica tendencia de las fuerzas militares a inclinarse a defender los intereses tradicionales. Si bien esto se da en el marco de la legalidad y del cumplimiento de ciertas obligaciones constitucionales, resulta una regularidad que se reactualizó en 2009 cuando el Ejército detuvo y exilió a Manuel Zelaya Rosales en su vivienda. Se puede encontrar un antecedente de esta preocupación en la obra de Manuel Rojas Bolaños, donde se expresa una explicación de las líneas generales del proceso político centroamericano de 1944 a 1979, estableciendo varias tendencias de orden general en cuanto a los actores implicados en la configuración de la hegemonía, como lo son los sectores tradicionales, oligárquicos y comerciales emergentes, que proceden de las capas asalariadas y profesionales. Este especialista califica la evolución del Estado oligárquico al moderno como una "transición ordenada", lo que refleja un consenso intacto desde el momento en que se formula una reorientación institucional con el fin de acomodarse a las condiciones exigidas por la integración al contexto capitalista (Rojas Bolaños).

Tomaremos como base analítica conceptos como hegemonía y consenso societario, desde la perspectiva de Gramsci y sus reinterpretaciones, particularmente las del cubano Jorge Luis Acanda González y el brasileño Darcy Ribeiro. Se propone al chavismo venezolano como una corriente político-ideológica que dio lugar al "zelayismo" o a una forma hondureña de populismo de izquierdas. La perspectiva de análisis será la de asumir el golpe de Estado como expresión de un choque de intereses y de ideologías definidas beligerantes al aflorar los temores ideológicos de una eventual "entrada" de Honduras en la órbita de Venezuela a través de la aprobación, en comicios democráticos, de la reelección de Zelaya.

También se utilizará, para caracterizar la intervención del Ejército en la "reconducción" de la coyuntura de desplazamiento forzoso del gobierno electo en las urnas en 2006, el concepto "pretorianismo", el cual proviene del lenguaje del estructuralismo y es aplicado asiduamente a las situaciones de transición entre 
un régimen de gobierno a otro en diversos esquemas, republicano, monárquico o despótico. El término pretorianismo nos lleva a pensar en una modalidad de gestión de la transición que supone un quiebre en la institucionalidad el cual provoca un vacío de poder. Este concepto en sí, según el venezolano Herbert Hoenecke, tiene una inspiración en las funciones ejercidas por los praetores (pretores), funcionarios militares selectos del Imperio Romano encargados de ejercer como la guardia del Emperador, los cuales guían la transición cuando existe manifiesta debilidad institucional y las instituciones políticas carecen de respuesta a una crisis de grandes magnitudes (Hoenecke). Para este especialista, el pretorianismo evidencia una crisis en la legitimidad, que según Max Weber (1864-1920), es aquella condición de aceptación del poder por parte de los que son gobernados. Esta legitimidad se expresa en la continuidad de la subordinación que la masa gobernada sostiene respecto a los liderazgos gobernantes, sean estos de tipo carismático, tradicional o legal (Hoenecke, 1986).

La literatura política ha tomado el concepto para describir la intervención de los militares en la gestión de una transición, seguramente, por tener como referente la actuación de la guardia pretoriana en algunos momentos clave de la Historia de Roma, cuando esta intervino en el recambio de varias figuras imperiales en los momentos de crisis terminal de un período imperial. Podría decirse que el concepto define el accionar de los pretorianos en coyunturas de apremio para la continuidad de la estabilidad del Imperio, pues regentaban la situación interviniendo directamente en la transición política, extralimitándose en el cumplimiento de sus funciones que, originalmente eran la custodia del gobernante. El esquema de roles en esta intervención se puede desglosar en varias dimensiones y actores: a) Una estructura de poder que se encuentra en crisis, ya sea por incapacidad de los gobernantes o fracturas del consenso del grupo en el poder, b) instituciones garantes del consenso, c) un grupo anexo, con funciones orientadas a la seguridad y d) el conjunto de la sociedad civil que no tiene participación ni implicación directa ni en la definición de los acuerdos políticos ni en la resolución de la emergencia coyuntural, la situación crítica puntual.

El primer apartado del trabajo constituye una contextualización histórica de los actores y sectores sociales confrontados en la coyuntura golpista, esto incluye una búsqueda del horizonte que generó la cultura autoritaria que caracteriza a la sociedad hondureña y en gran medida, la centroamericana; luego se presenta la irrupción del proyecto de Manuel Zelaya como una respuesta a las expectativas populares postergadas desde el inicio de la existencia del Estado; y para finalizar, se desarrolla una caracterización del zelayismo como variante particular en el espectro político, así también se manifiesta un balance acerca de las condiciones políticas que permitieron la conexión del gobierno hondureño con un movimiento en alza y auge en la región la pasada década, el chavismo y el Socialismo del Siglo XXI. 
La segunda parte del trabajo alude al afianzamiento de la derecha que se registra en Honduras desde el golpe de Estado de 2009. Se examinan aquí aspectos intersubjetivos, como la mentalidad conservadora que ha predominado en los gobernantes, provocando la intervención de las fuerzas armadas en la gestión de la resolución de esta crisis, un aspecto que también tiene arraigo histórico y cultural como fuente generadora de prácticas políticas. Como punto final, se presenta el resultado práctico de la descontinuación del gobierno de Zelaya Rosales, una década de afianzamiento de la derecha con los gobiernos del Partido Nacional. Finalmente, se incluyen conclusiones que expresan algunos juicios a los que se llegó en el transcurso del proceso de construcción argumentativa de este aporte a la comprensión de las causas y consecuencias del golpe de Estado.

\section{El golpe de Estado: "Nuevo episodio" que evidencia la perduración de viejas prácticas en el seno de la moderna democracia}

En Centroamérica, el desarrollo de la ideología liberal encontró compatibilidad en la mentalidad oligárquica, clerical y terrateniente que era parte del patrimonio de las clases dominantes provocando el desarrollo de un liberalismo sui géneris, en el que las innovaciones ideológicas como la libertad de cultos y la laicización de la educación coexistían con prácticas clientelares y caudillistas. El período liberal entonces, ve cómo se forjan nuevos liderazgos sobre un terreno plagado de ideas, argumentos y prácticas que en otro lugar serían considerados atavismos, pero en Iberoamérica son parte de las tradiciones políticas.

La pervivencia de este orden se aprestó para configurar el perfil con el cual las sociedades llegaron al siglo XX y transcurrieron durante gran parte de este. $\mathrm{Al}$ ser estas las condiciones que permitieron el desarrollo de todas las formas productivas que caracterizaron a los países de la región, queda asociado al andamiaje ideológico mencionado la legitimidad y carácter tradicional de las formas propias de consenso. Debido a que esta ideología permeó las prácticas sociales, la aceptación al status quo por parte de las mayorías orientó a la aceptación y reproducción de dicho imaginario en las prácticas sociales y políticas preñadas de caudillismo y paternalismo, lo que es resultado del consenso autoritario, en este caso de carácter oligárquico respaldado por el Ejército.

En el vocabulario técnico de la Ciencia Política clásica, estas condiciones se resumen en el concepto de tutelaje, instaurado como normativa en la práctica o cultura política de las élites. Esta condición se expresaba, en la praxis, con acciones que daban lugar a pensar en la existencia de un consenso democrático asumido como legítimo y generalmente aceptado por la asistencia a las urnas y el acatamiento de las disposiciones de los organismos del Estado, es decir, la obediencia. 
Pero como ninguna hegemonía es infalible, la gradual penetración del pensamiento crítico - generada a partir de los inevitables cambios que dieron lugar a la proletarización y la creación de grupos intelectuales alternativos a los oficiales- en sus variantes anarquista y mutualista en un principio y luego con movimientos sindicales de mayor combatividad tras la maduración del pensamiento socialista, esta hegemonía fue contestada, como en países vecinos, con posturas transgresoras y de orientación revolucionaria en el marco de algunos movimientos sociales de orientación popular.

En el caso de Honduras, estas dieron lugar al desarrollo de trayectorias de lucha política que, finalmente, terminaron engrosando el martirologio de las luchas populares, tal como sucedió con Pablo Waingwright, ejecutado en Guatemala hacia 1932 por órdenes de Jorge Ubico Castañeda. También, entre estas primeras figuras de orientación izquierdista se encuentra el resonante nombre de Juan Pablo Umanzor, un brillante adjunto del "General de Hombres Libres", victorioso muchas veces al mando de su falange latinoamericana sobre los Marines en Las Segovias de Nicaragua.

Queda esbozada entonces, la partición del espectro político entre un campo que continúa reproduciendo las directrices ideológicas y las prácticas que llegaron a tradicionalizarse con la consolidación de la versión local de liberalismo -el cual generó y configuró el pacto fundacional del Estado Nación Moderno-, consistiendo en recursos para la estabilidad y la continuidad sistémica y otro que, ajeno a cualquier participación en el establecimiento del juego político, pugna por "atrapar" adherencias desde la convocatoria y planteamiento de cambios esenciales.

A pesar de que, para fines de análisis, necesariamente se ha de "partir" el espectro político de Honduras en dos campos, el escenario que se esboza también permite configurar varios escenarios posibles para un pacto societario. La convicción de que una opción política o ideológica excluye totalmente a la otra no es viable y menos aún en la política, donde los acuerdos y alianzas intersectoriales resultan, muchas veces, imprescindibles para el desarrollo y la existencia misma de una estructura.

Si esto, en el marco de un ejercicio explicativo, se aplica a la problemática planteada por el "giro" del presidente Zelaya a la órbita bolivariana, podemos encontrar la raíz de la animadversión que el mismo causó en los sectores que, tradicionalmente, han preparado el ambiente propicio para la reproducción de sus intereses desde la posición del poder: Ejército, empresarios y sectores de múltiples proveniencias y extracciones aglutinados en la burguesía.

\section{En busca de los "antecedentes", un poco de historia}

El inicio de este trabajo conlleva pensar en una hipótesis para explicar el golpe de Estado ocurrido ya hace diez años. El quiebre abrupto al gobierno de Manuel Zelaya, elegido democráticamente en 2005, tuvo lugar como expresión de fuerzas sociales y 
políticas internas y externas que se enfrentaron a partir de que se insinuaba un recambio hegemónico que amenazaba la primacía de los intereses tanto de Estados Unidos como de los sectores dominantes tradicionales.

Históricamente, no solamente Honduras, sino también toda la zona centroamericana, ha forjado una idiosincrasia política caracterizada por el autoritarismo y la inexistencia de una democracia inclusiva, que permitiera la obtención de condiciones de vida dignas para la mayoría de la población. De los países existentes en la actualidad en los otrora territorios del antiguo Reyno de Goathemala y la República Federal de Centroamérica, solamente Costa Rica ha tenido éxito en establecer un consenso societario orientado a la obtención de una hegemonía de tipo democrático. El resto de los países tienen en el haber de su historia política gran número de quiebres violentos a gobiernos y regímenes civiles y militares tanto dictatoriales como electos popularmente (Torres Rivas).

En Honduras, a pesar de que no se desarrollaron longevas dictaduras como en Guatemala ni se entronizó ningún clan familiar en el poder como sucedió en Nicaragua con los Somoza, existió la supeditación del gobierno a intereses económicos que, en algún momento, precisaron de la "mano dura" para consolidar el modelo autoritario cuando el mismo se halló en crisis. Sobre todo la bananera United Fruit Company (UFCO) colocó bajo sus órdenes a funcionarios suyos como el abogado Juan Manuel Gálvez, que ocupó la presidencia entre 1949 y 1954 (Arévalo Bermejo). ${ }^{1}$

La cultura política entonces, tuvo una conformación bajo los cauces del autoritarismo criollo que, sobre todo después de la Reforma Liberal, configuró el Estado, las instituciones y la lógica que se transformó en base fáctica para la existencia de una forma de consenso societario. En este contexto, el Ejército desempeña una función de respaldo al ordenamiento establecido, una de las clásicas funciones asignadas en los sistemas republicanos cuyo régimen legal y político se inspira en el ideario liberal. ${ }^{2}$

Hablar de golpes de Estado en Centroamérica es referirse a una constante en su Historia Política que tiene lugar debido a que estos han sido reacomodos entre los diversos bloques y fracciones de la clase dominante en el poder. Esto no significa que el ocurrido el 28 de junio de 2009 posea idénticas características y móviles que otros, en los que, una explicación proveniente del ámbito de las Ciencias Sociales da cuenta de un reacomodo entre las fracciones oligárquicas que componen el bloque identificado terminológicamente como burguesía (Torres Rivas).

Algunos escritos abordan los golpes de Estado en tiempos recientes, destacando el de Barrios Oviedo (2014), quien revisa el balance hegemónico que rige en la región. Retomando trabajos pretéritos, destaca el aporte de Pérez (1998) y la obra de Rojas Bolaños, la cual explora la cultura política de Centroamérica a la luz del proceso de configuración del Estado moderno entre 1944 y 1979, en el que se expresa una explicación de los golpes militares ocurridos en este momento. 
La singularidad del movimiento hegemónico moderno se encuentra en el involucramiento de una tercera fuerza, que se integra a la lucha entre sectores consolidados y emergentes locales: el movimiento de integración regional impulsado por Hugo Chávez desde el inicio de su irrupción en la escena política latinoamericana, con su primer mandato en el año 1999. Esto no podría afirmarse si no existiera una evolución de la administración Zelaya Rosales hacia las líneas conformadas en torno al proyecto bolivariano, que pugnó, en momentos de su expansión, por la formación de una alianza regional opuesta a la lógica de los intereses estadounidenses y a la reproducción de la subordinación a los mismos en el contexto del ALCA, la cual ha configurado las relaciones internacionales y la política interna de los países centroamericanos.

Entre los referentes de estudio y profundización sobre la influencia del chavismo fuera de Venezuela, Judith Valencia aborda la forma en que el proyecto de Hugo Chávez llegó a confrontar a los poderes hemisféricos al exterior, chocando con Estados Unidos en momentos del relanzamiento del ALCA por la administración Bush Jr. (2001-2009). Este aspecto, sumamente importante para dimensionar el papel de Venezuela en la asistencia al gobierno de Manuel Zelaya en Honduras, también lo desarrolla Vanbiervliet (2013), quien analiza las políticas regionales de Chávez como parte de una agenda que se concretó en nuevos organismos de integración económica como el proyecto de cooperación energética Petrocaribe, fundado en 2005, y la Alianza Bolivariana para las Américas, que incluyó a Honduras en 2008, durante el gobierno de Manuel Zelaya.

Se trataría entonces de un nuevo episodio donde, como en el pasado, alguna fractura del pacto político que rige en el país se procuraría restañar o recomponer con la remoción de un gobernante o funcionario clave en la jefatura de los poderes legislativo o judicial. Tal es la constante histórica que arroja el análisis de la cronología de los gobiernos que se han sucedido en el poder, lo que indica ya la existencia de una estructura de pensamiento, prácticas y lógicas de la acción política.

\section{Giro a la izquierda de "Mel" Zelaya, una desviación que había de corregirse}

La elección de Manuel Zelaya Rosales en 2005 no preludió, en un principio mayor cambio en la orientación del gobierno en Honduras. Después de la más reciente finalización de la intervención militar en la vida política y el establecimiento del pacto democrático de 1982 cristalizado en una nueva Constitución, de inspiración oligárquica y neoliberal (Prieto Rozos), no se había presentado mayor perturbación de los períodos de gobierno, lo que hizo posible la sucesión de seis presidentes ganadores de los comicios celebrados a cada cuatro años. ${ }^{3}$

La gran mayoría de los gobernantes, desde entonces, provenían de filas del empresariado y de familias que, de alguna manera, han detentado puestos claves en el poder legislativo y judicial. Como sucede en los países vecinos, aparentemente se ha 
superado la dependencia de los caudillos y de liderazgos carismáticos y el aparato político ha sido asimilado a una esfera de hegemonía del empresariado y sus operadores, lo cual brinda una continuidad a sus agendas y programas. Sin embargo, el hecho de que Zelaya fuese elegido en el marco legal prohijado según las orientaciones establecidas, no conjuraba se realizara un "vuelco" ideológico que planteara disidencia o no sujeción a los planes de los grupos dominantes, más aún cuando encontramos en este político rasgos oligárquicos.

Lo anterior tuvo lugar a partir de condiciones particulares de la política regional y mundial. Para 2006, en la región se dejó sentir el influjo del movimiento bolivariano impulsado desde Venezuela por el gobierno de Hugo Chávez Frías. Propugnando el "socialismo del siglo XXI", Chávez procuraba construir un espacio político emancipado de las políticas estadounidenses, las cuales habían configurado una dinámica particular desde el inicio del siglo anterior, inaugurado con un ímpetu imperialista subyacente en la política de la zanahoria y el garrote de Roosevelt y la diplomacia consular de Taft que pretendía hacer del Mar Caribe el mare nostrum. Esta orientación política y en relaciones exteriores es profundizada por Prieto Rozos, quien explica el recrudecimiento de la agresividad propia del imperialismo norteamericano después del 11 de septiembre de 2001 y la guerra contra el terrorismo, así como los aportes de Petras en el libro Imperialismo y Barbarie.

El gobernante venezolano, en aquellos años, efectuaba y sostenía alianzas con mandatarios afines ideológicamente, impulsando y fortaleciendo una orientación hacia la izquierda y buscando la formación de un bloque político opuesto a la hegemonía estadounidense. De base ideológica socialista y proveniente de un movimiento cívico proscrito forjado en las filas de la institución armada -el Movimiento V República-, una vez presidente, procuró emular el rol de Cuba como referente de las izquierdas en el hemisferio, así como planteó la recuperación de la autonomía y la independencia política y económica en un momento álgido de la ofensiva estadounidense por reforzar su hegemonía a través del lanzamiento del Área de Libre Comercio de las Américas (ALCA). ${ }^{4}$ Esta propuesta encontró resonancia en varios liderazgos de la región, muy especialmente, en América del Sur, donde se consolidó una tendencia sur-sur que confrontó la hegemonía del Norte; los planes de Chávez fueron secundados por Luiz Inácio "Lula" da Silva (2003-2011), de Brasil, Néstor Kirchner de Argentina (2003-2007), Fernando Lugo de Paraguay (2008-2012) y Rafael Correa de Ecuador (2007-2017). Como se puede comprobar, todos ellos coincidieron, en mayor o menor medida, con los años de apogeo del chavismo.

Chávez procuró ganar adherencias a través del lanzamiento de la Alternativa Bolivariana para las Américas (ALBA) -después renombrada como "Alianza"- y los tratados de abasto energético bajo precios preferenciales con la iniciativa denominada Petrocaribe, a la cual logró circunscribir a varios países de la cuenca caribeña, 
incluyendo a varios países del bloque CARICOM y la Commonwealth. Estos avances le aprestaron una base de países aliados que le convirtieron en el factor de muchos gobiernos que le secundaron en su esfuerzo por generar la emancipación económica de la región (Prieto Rozos). Esta proyección fue parte de la estrategia geopolítica del chavismo en la región y el intento por generar un proyecto y proceso de integración que coincidía con el espacio de dominación tradicional de Estados Unidos.

En Centroamérica, la influencia venezolana fue sensible en gran medida en Nicaragua, donde, por afinidad ideológica, el movimiento sandinista tomó a Chávez como uno de sus aliados más conspicuos. Esto produjo la vuelta al poder del expresidente sandinista Daniel Ortega Saavedra y el lanzamiento de un proyecto que, al igual que el bolivariano, buscaba mostrar la actualidad y vigencia del socialismo en medio de una ofensiva conservadora del poder estadounidense que complementaba dos décadas de impulso al neoliberalismo y la imposición de un consenso regional acorde a sus intereses y programas. ${ }^{5}$

Zelaya, una vez enfrentado a los poderes tradicionales, no pudo resistir la influencia de Chávez. En poco tiempo, generó algunas medidas de corte populista que no fueron bienvenidas por los grupos dominantes, restándole apoyo y legitimación en los espacios empresariales. Es obvio que estos sectores resintieron el aumento salarial que su gobierno concedió a los empleados estatales y la inclusión de Honduras en el ámbito de la influencia económica y política de la Venezuela chavista.

Estos aspectos constituyeron una incitación a los grupos de tendencia conservadora para agudizar su oposición al gobierno y hacer de la continuidad de Zelaya un riesgo para sus intereses. En este accionar produjo la intensificación de los temores ideológicos, puesto que también el giro de Zelaya a la órbita bolivariana significaba un posicionamiento de lucha contra los poderes hemisféricos tradicionales. Esta circunstancia también reforzó los prejuicios contra la izquierda, lo que incidió también en la represión de los movimientos de la sociedad civil, de larga trayectoria no solamente en Honduras sino en la región.

\section{El zelayismo en el marco de una década de resurgimiento para los regímenes nacional-populares en Iberoamérica}

A pesar de que una lectura estratégica profunda puede encontrar el vuelco de "Mel" Zelaya a posiciones de lo que se conoce como "izquierda" como un desempeño errático, que retó a los grupos dominantes por ser contrario a condiciones del consenso societario, un análisis focal y coyuntural del golpe de Estado no puede desdeñar o menospreciar el hecho de que la primera década del siglo XXI fue pródiga en la existencia de gobiernos distanciados de las posturas y programas neoliberales asumidos por las derechas tradicionales, y sus expresiones y versiones modernas que han encontrado oposición en los liderazgos populares (Llanos). 
La definición de izquierda, tal como la comprendemos aquí, abreva en los análisis de las polaridades en el espectro político hondureño que definen las preferencias electorales desde la reinstauración de la democracia, como lo planteado en IUDOP (2007), donde se señala que, desde 1981, fecha de la convocatoria a nuevos comicios después de varios gobiernos de facto, ha existido una alternancia constante de dos formaciones de derecha, el Partido Liberal y el Partido Nacional. En la coyuntura del golpe de Estado contra Manuel Zelaya, Capineta revela que, para la coyuntura del "golpe técnico", la izquierda está representada en el parlamento hondureño por el partido Unificado Democrático, uno de los cinco con representación legislativa. Miembros de este partido, los diputados Marvin Ponce y Tomás Andino, apoyaron a Manuel Zelaya cuando se opusieron a la iniciativa del democristiano Ramón Velásquez Nazar de investigar al presidente por "conducta impropia por no acatar a las disposiciones de los órganos jurídicos del país", esto en referencia a la postura tomada por la Corte Suprema ante la consulta popular lanzada por el mandatario. Esta afirmación excluye a los movimientos sindicales, indígenas y demás, que discursivamente, presentan siempre simpatías por la izquierda (Cruz Alas).

El protagonismo que en este análisis se le confiere al proceso de expansión del proyecto bolivariano reside en su innegable influencia en los contextos geográficos donde ha tenido lugar la hegemonía estadounidense. En aquellos momentos, la trascendencia de las acciones de Hugo Chávez encontró un escenario en el que los grupos tradicionales se plegaban a las directrices de la potencia norteña debido al reforzamiento de la hegemonía que planteaba la política exterior de los neocons durante la administración de George Bush Jr. (2001-2009). El apogeo de la administración Bush Jr. se caracterizó por una política exterior agresiva con las guerras e invasiones de Afganistán en 2001 e Irak en 2003. Coincidentemente, estos son los años en que emergió el chavismo en alianza con el castrismo, lo que escenificó un enfrentamiento discursivo a gran nivel.

En aquellos años, muchos partidos de izquierda se sumaron al posicionamiento venezolano, centrado en el antiimperialismo, la autodeterminación de los pueblos y la inclusión económica, política, social y económica. El presidente Chávez, con su retórica antiimperialista y la ofensiva ideológica planteada mediáticamente con la resonancia de sus discursos y alocuciones de gran cobertura, estimuló y aglutinó a muchos liderazgos que habían permanecido en posiciones de marginalidad y con pocas posibilidades de acceder al poder en el contexto de la democracia electoral.

Para la historia política de la región, el auge del moderno bolivarianismo supone un ingrediente exógeno que se integró pronto a la dinámica política que se vivencia en las subregiones periféricas. Anteriormente, ningún movimiento político o ideológico generado en la región había pugnado por establecer nuevas condiciones para la hegemonía y reformulación de las directrices para el Estado. 
El período de gobierno de Manuel Zelaya (2006-2009), coincide con el apogeo del llamado "Socialismo del Siglo XXI", ha pasado a la Historia como un momento de sintonización de una estructura política formulada según los planes de una oligarquía conservadora, aliada y dependiente del imperialismo, con movimientos de clara orientación nacionalista y de construcción de nuevas condiciones para las relaciones internacionales.

A través de su vinculación al proyecto socialista surgido en Venezuela y madurado por Hugo Chávez, el gobierno hondureño planteó una adherencia a un proceso que buscaba la reconfiguración de los contrapesos entre los diversos intereses confluyentes en la región, una tarea titánica si se revisa la Historia y se comprende la supeditación de los gobiernos a potencias externas como una característica intrínseca de los países de la región en lo económico.

Esta circunstancia, a lo interno, dispuso a los elementos más recalcitrantes del espectro político e ideológico a recelar de las medidas del presidente, percibiéndolo como gestor de un cambio político que buscó y obtuvo una validación positiva de gran parte de los sectores populares. Aquí se sostiene que el fortalecimiento de la derecha en Honduras después del golpe contra el gobierno de Manuel Zelaya obedece al rol protagónico tomado por las fuerzas armadas. El arresto de Zelaya y la represión mostró un posicionamiento decidido en contra suya, amparando las decisiones de la Corte Suprema, presidida por Micheletti. Los medios de comunicación locales e internacionales manifestaron que el corte abrupto de este gobierno era producto de una alianza de fuerzas conservadoras de derecha, cuyas acciones trasparentaron un acuerdo.

Para explicar el peso ideológico de esta forma de interpretar el populismo de izquierdas que Chávez hizo propio del "Socialismo del siglo XXI", debe tenerse presente que, muchas veces, el análisis de las situaciones coyunturales suele excluir el análisis del factor subjetivo, de las emocionalidades desatadas por los gestores de programas y proyectos políticos. La teoría política con más "éxito" en ello debe introducir variables que incluyan la posibilidad de abordar la subjetividad y la sensibilidad de las masas al discurso y posicionamientos ideológicos que se anexan al actuar de los liderazgos y ejercicio de la convocatoria mediática, en tiempos modernos, mediada por la publicidad.

El análisis del moderno populismo, reactivado con la emergencia del proyecto bolivariano y la resonancia adquirida por la coincidencia de un triunfo de las opciones políticas de orientación izquierdista en la primera década del siglo XXI merece un desarrollo más amplio, debido a que el mismo significó una respuesta a las demandas populares que, obviamente, la "democracia tradicional" y el programa neoliberal no pudieron dar. Recurriendo a viejas consignas, el renovado populismo trató de desplazar a las derechas y las opciones centristas que tuvieron amplia presencia en el espectro político de las últimas décadas del siglo anterior al punto de ocupar el lugar de las alternativas. 
En la región caribeña y centroamericana, de las cuales forma parte Honduras, al principio del siglo XXI tuvo lugar un fenómeno de relanzamiento de los programas de la izquierda dirigido a ocupar un sitial en el espectro político que se le negó en tiempos de la Guerra Fría, cuando optar por dicha orientación era un claro sesgo sancionado doblemente: a) Estigmatización de las instituciones y la legalidad interna de los países, aspecto político interno y b) Sanción desde el exterior por los poderes hemisféricos, enfrentados en la mayor parte de la segunda mitad del siglo XX a una lucha por la erradicación de movimientos sociales y políticos afines al socialismo.

Haciendo uso de la cronología y el método analógico, puede establecerse que durante el gobierno de Manuel Zelaya Rosales existió, paralelamente, un conjunto de gobiernos caracterizados por la orientación ideológica afín y compatible al chavismo. Aunque, la formación de un bloque político quedó pendiente y descontinuada con la muerte de Chávez, desde su ascenso al poder y el lanzamiento de su proceso de reforma del Estado a través de diversas iniciativas reformadoras (que emanaron de la aplicación de la nueva legitimidad construida por la V República) varios países secundaron su posición si bien tuvieron cuidado de no integrarse del todo a la retórica "antiyanqui" que el venezolano convirtió en parte esencial de sus discursos.

La orientación de sus intervenciones públicas se derivó de un repertorio discursivo nutrido de proclamas autonomistas y de lucha por la emancipación de la región latinoamericana, con lo que refrendaba el papel anteriormente desempeñado por Fidel Castro Ruz, su mentor ideológico y principal referente histórico además del pensamiento de Simón Bolívar y Ponte, "El Libertador" (Petkoff). En diversos ambientes y contextos, el militar retirado predispuso contra sí a los sectores recalcitrantes de las derechas locales y a los poderes hegemónicos hemisféricos, que históricamente han manifestado compatibilidad en el sostenimiento de las estructuras económicas.

Los inicios de siglo fueron tiempos en que la derecha, gestora de la continuidad de la crisis causada por la profundización del neoliberalismo a fines de siglo, se encontró retrocediendo ante el empuje de muchos partidos de orientación similar o compatible a la de Chávez. Tal vez el caso más evidente de ello se encuentra en el boliviano Evo Morales Ayma (n. 1959), actualmente en el poder, miembro y líder del MAS (Movimiento hacia el Socialismo). A la cabeza de tal movimiento, el otrora vocero de los campesinos cocaleros de la región de Chapare lidera un proyecto de empoderamiento de las clases populares y fortalecimiento de un Estado que ha sido, tradicionalmente, un servidor de las compañías mineras que explotan el suelo boliviano (Prieto Rozos).

Además de Evo Morales, en el tiempo que se dio la coyuntura del golpe a Manuel Zelaya también contaba con gran popularidad en la región Rafael Correa, un economista ecuatoriano protagonista y gestor de un movimiento político renovador pródigo en elementos socialistas que, al postularse por la llamada "Alianza País" obtuvo el respaldo de gran parte del electorado, haciéndole presidente constitucional el 15 de enero de 2007, después de decenios de administraciones erráticas, plagadas de 
corrupción (Prieto Rozos). La última crisis de gobernabilidad sufrida por el país fue la que tuvo lugar en el gobierno del militar derechista Lucio Gutiérrez, que fue destituido por el Congreso después de que ocurrió una grave fractura en la alianza que le apoyaba (Lozano).

Puede decirse que, junto a Morales, este presidente siguió los pasos de Chávez, puesto que llevó a cabo algunas medidas de fuerza producto de reformas constitucionales, al estilo del venezolano, marcando una impronta en la praxis política de la región que se extendió a una decidida ofensiva contra los lineamientos establecidos por Estados Unidos en materia económica, militar y estratégica.

A pesar de que existían otros gobiernos de izquierda, en la región latinoamericana Venezuela primero, luego Bolivia y por último Ecuador se constituían en paradigmas de una nueva gobernanza y de orientación política. Ellos enfilaban a sus países a secundar a Venezuela, enfrentada a la estigmatización y presión estadounidense y la ofensiva de la derecha conservadora regional. El impulso popular al chavismo fortaleció al bloque en el poder después del golpe de Estado de abril de 2002, luego del cual Chávez fungió como gestor de un nuevo ordenamiento continental, promoviendo la independencia con respecto a los centros del poder mundial.

El concepto "zelayismo" implica entonces una significación desprendida de esa vinculación que el gobierno hondureño tuvo con el populismo chavista, de fuertes componentes autoritarios (Boersner). Al romper los esquemas de los gobernantes pertenecientes a la línea oligárquica y virar, no hacia una posición de centro, sino que hacia una dirección contraria a su extracción, origen y clase social marca una tendencia inédita cuyas motivaciones conviene explicar a profundidad para explicar el golpe de Estado en Honduras.

\section{La vinculación con el Socialismo del Siglo XXI, el "pecado mortal" de Zelaya}

Con lo expuesto anteriormente, queda establecido un marco histórico y estratégico que hizo posible la confluencia y compatibilización del gobierno hondureño con una fuerza emergente surgida en aquellos años: el chavismo en expansión regional. Como consecuencia inmediata, Zelaya fue apoyado por Hugo Chávez de diversas maneras. Al igual que otros países de la región, en Honduras se instauraron algunos programas sociales una vez que tuvo lugar el acercamiento del líder venezolano. ${ }^{6}$

Debido a la participación hondureña en el ALBA (miembro de este consenso para abril de 2009), tanto la educación, como la agricultura, ganadería y otros rubros resultaron beneficiados con las donaciones venezolanas durante el cuatrienio de gobierno. En 2011, cuando la derecha gobernaba de nuevo de mano del Partido Nacional, Honduras, gravemente afectado por carencias alimentarias, recibió un lote de alimentos de procedencia venezolana como parte de los apoyos proyectados por el Banco 
del ALBA, una iniciativa de Chávez para coadyuvar al desarrollo regional a través de créditos (Prieto Rozos).

Esta filiación de Zelaya podría explicar, en gran parte, el apartamiento violento del que fue objeto una vez que introdujo, a instancias de una cuarta urna para consultar a la población sobre si estaba de acuerdo o no en convocar a una Asamblea Nacional Constituyente el 28 de junio de 2009, cuando se llevaban a cabo elecciones generales. Cuando él estableció esta medida, el Ejército se negó a repartir la cuarta urna, las cuales fueron recuperadas por el presidente a la cabeza de una manifestación de simpatizantes (Prieto Rozos).

Según se viene estableciendo, esta tentativa de introducir reformas constitucionales, -entre las que se alega se introduciría la posibilidad de la reelección, al estilo de Hugo Chávez- constituyó el detonante de una intensa campaña de desprestigio para Zelaya, la cual fue apuntalada por las declaraciones del Poder Judicial, un instrumento clave en el sostenimiento de las condiciones favorables a los grupos dominantes. La estrategia de las fuerzas que derrocaron a Zelaya conllevó una participación sumamente importante del Ejército, cuyos mandos coincidieron con la posición de la Corte Suprema presidida por Roberto Micheletti, presidente interino tras su separación del mando. Resultó evidente la instrumentalización de las fuerzas armadas cuando tuvo lugar el arresto de Zelaya y se realizaron las manifestaciones de sus adherentes, asumiendo el Ejército un papel distinto al derrocamiento de otros presidentes, como Fernando Lugo y Dilma Rouseff, lo que evidencia una vinculación a los intereses dominantes de una fuerza armada que se supone neutral en los regímenes democráticos.

La intimidación, amordazamiento y expulsión del país de las que fue víctima en horario nocturno por hombres encapuchados que allanaron su vivienda y el posterior envío en ropa de dormir a Costa Rica fue la expresión más nítida del sentir de la cúpula militar y empresarial, cuyas acciones estaban coludidas en dicha coyuntura, pues el presidente había ya logrado incomodarlos con destituciones de miembros de la jerarquía y algunas medidas antimonopolistas en los rubros de importación de combustibles y medicamentos (Prieto Rozos). En Honduras, bajo el gobierno de Zelaya, tuvo lugar el programa de alfabetización "Yo sí puedo" de influencia cubana, ensayado en Venezuela (Bográn), así como se realizaron algunos préstamos para pequeños productores agrícolas. También Hugo Chávez pugnaba por incluir a este país, a través de la alianza con Zelaya, en el área cubierta por el proyecto de colaboración energética Petrocaribe.

La reacción popular al golpe no se hizo esperar y se manifestó en la creación de un Frente Nacional contra el golpe de Estado, una instancia multisectorial que expresó su desconocimiento al gobierno de Roberto Michelletti y a sus medidas (Prieto Rozos). A pesar de que la espectacular vuelta de Zelaya el 21 de septiembre y de su asilo en la embajada brasileña viniendo de Nicaragua donde se había asilado, este no fue restituido en el cargo y debió conformarse a una posición opositora desde la cual 
era imposible relanzar el proyecto político que lideraba. Tal fue el final del zelayismo. ${ }^{7}$ Después, sobrevino un período en el cual, la persecución y la represión de los simpatizantes de Zelaya, los políticos y liderazgos alternativos marcaron una transición hacia el empoderamiento de la derecha en tres períodos de gobierno del Partido Nacional.

\section{El afianzamiento de la derecha en Honduras después del golpe de Estado}

\section{El "trasfondo subjetivo": Los temores ideológicos de ayer y hoy}

Desde el punto de vista de la Historia, las élites dominantes centroamericanas, a partir de la independencia en 1821, han consolidado dos grandes líneas ideológicas que se han convertido en el referente de lo que podríamos llamar "ideología oficial". Estos son el conservadurismo y el liberalismo, sumamente importantes en la práctica política de la región inclusive en las polémicas entre intelectuales antes de que se diera la particular emancipación de 1821, en las tertulias de intelectuales que dieron lugar a la planificación de la forma en cómo se realizaría la independencia. ${ }^{8}$ Después de la emancipación, los conservadores dominaron la escena política, sosteniendo una colaboración y alianza entre oligarquías tradicionales, Iglesia y liderazgos laicos urbanos y campesinos. Después del triunfo del liberalismo, aunque oficialmente los gobiernos han proclamado su inclinación a la modernización de la práctica política, reproducen mecanismos de explotación propios de la época colonial y, una vez consolidados en el poder, acomodan su discurso a diversas condiciones y circunstancias, sosteniendo el consenso autoritario. De fondo, las aspiraciones de la ideología liberal procuran, en los hechos y decisiones, reforzar la reproducción del sistema capitalista y la centralidad del mercado.

Estos organismos lograron afianzar en el poder a los representantes de los grupos terratenientes que ejercían la minería, la ganadería extensiva y el comercio, dando lugar a la formación del Estado moderno que se basó en la estructura del molde republicano, funcionalizado aquí bajo las condiciones propias de la realidad de cada uno de los países bajo una orientación paternalista y oligárquica, que procuró establecer un consenso societario acorde a dicha direccionalidad. En una primera instancia, esto tuvo como consecuencia un ordenamiento social y político que reprodujo la orientación básica de la articulación consensual, la sociedad tutelada en la que tuvo lugar la concesión de la ciudadanía a las mayorías bajo las condiciones propias de la diferenciación estamental.

Una vez consolidado dicho ordenamiento, la práctica de las directrices insertas en los instrumentos jurídicos normativos estableció claramente cuáles serían los parámetros rectores del juego social y político. La legislación liberal, inspirada en el positivismo, suele establecer elementos legales que sancionan las faltas al orden establecido, teniendo como tal aquel que han forjado los grupos progresistas que han triunfado en el afán de llevar a la Humanidad al Orden, el Progreso y la Modernidad. 


\section{¿Pretorianismo necesario para "corregir el rumbo"?}

El análisis y explicación del golpe de Estado de Honduras da lugar para incorporar el concepto del pretorianismo a su lectura e interpretación política profunda. Esto puede afirmarse debido a que, la sociedad hondureña, por sus particularidades, puede encajar en lo que según Hoenecke, Thomas Huntington entiende como "sociedades pretorianas", caracterizadas por una evidente debilidad estructural para restañar las rupturas del pacto y la incapacidad para lograr una resolución a las problemáticas dentro de las pautas de este (Hoenecke).

Por tanto, conociendo la Historia política de la región y teniendo presente sus características autoritarias, conservadoras y desiguales, podemos decir que la misma facilidad con que se han reproducido las dictaduras, guerras internas y golpes de Estado han existido, en las fuerzas armadas vocaciones pretorianas. Reteniendo el carácter de la evolución política de Centroamérica, puede reconocerse que, a excepción de Costa Rica, todas las sociedades poseen características propias de aquellas en que un grupo militar que interviene en los recambios del poder termina condicionando el desarrollo y la resolución de un episodio crítico coyuntural en el que "salen a la superficie" las fricciones y contradicciones intersectoriales mediatizadas.

Atendiendo a la demanda de análisis coyuntural y con respecto de la crisis hondureña desatada en 2009, se puede comprender que el rol pretoriano fue ejercido ahí por las fuerzas armadas. Cabe destacar en este aspecto el hecho de que, los militares tuvieron una gran uniformidad con respecto a las medidas tomadas contra Zelaya, no existiendo, a la fecha, referencia de mayor pronunciamiento en apoyo a este cuando el jefe castrense Vásquez intervino para desalojar al gobernante.

Esta cohesión solamente puede darse como expresión de una disposición de la institución militar a orientar su accionar en una dirección, cancelando las posibles disidencias que podrían presentarse de existir mayor diversidad ideológica en sus filas. Una de las posibles explicaciones a esta condición puede ser la impregnación ideológica en los integrantes de las fuerzas armadas de una versión sumamente particular de nacionalismo, un aspecto intersubjetivo que no suele asimilarse a los esquemas analíticos de explicación a las acciones de las fuerzas armadas en momentos coyunturales y de recomposición hegemónica.

Un conocimiento por demás mediano del clima interno de las fuerzas armadas puede servir también para develar condiciones que no pueden percibirse prima facie. Esto es un aspecto metodológico por tomar en cuenta, debido a que históricamente, la idiosincrasia política de Centroamérica inclina a que los Ejércitos Nacionales se constituyan en un apéndice del poder económico y, por tanto, prive en su accionar el interés privado sobre el público.

Debido a ello, aspectos como la vigilancia de la seguridad pública y el garantizar el respeto a la Ley y la Constitución resultan aspectos secundarios por estar coludidos 
los intereses de los grupos dominantes con las instituciones garantes y promotoras de la legalidad. Asimismo, los subordinados pueden plantear una contestación desde la subalternidad, tal como lo proponen Ranajit Guha y su escuela, lo que "da vuelta" a la certeza de los seguidores a rajatabla de Max Weber (Modonessi). La teoría, por más "clásica" o consolidada en los ámbitos discursivos y círculos docentes e investigativos, no puede determinar o condicionar los hechos y procesos que se desarrollan a posteriori. ${ }^{9}$

El pretorianismo, entonces, viene siendo, a la vez, una característica y fenómeno con abundante presencia en las coyunturas conflictivas y en los momentos decisivos de la recomposición y, en el caso de Honduras, el redireccionamiento de la orientación política del gobierno. A partir del análisis de las condiciones que plantea la dominancia de la derecha, podría concluirse que, a fin de cuentas, la intervención del Ejército era necesaria para las élites, que podían encontrar sus intereses dañados una vez que, otro período presidencial, le permitiría a "Mel" Zelaya el inicio de un proceso de refundación del Estado o de imposición de reformas que, sin generar un cambio total, revolucionario, disminuyeran sus privilegios.

\section{Diez años de gobiernos del Partido Nacional: El repunte de la derecha después del golpe}

Después de que las fuerzas armadas desalojaron del poder a Manuel Zelaya Rosales, se instaló un gobierno provisional presidido por Roberto Micheletti Baín (1943), un empresario y político de larga tradición militante en las filas del Partido Liberal como el anterior. Fue electo presidente del Congreso Nacional tras las elecciones de noviembre de 2005 en las que se plasmó la continuidad de los mandatos electos cada cuatro años desde la "vuelta a la democracia" de 1982.

Cuando tuvo lugar el golpe de Estado que derrumbó el gobierno de Zelaya en junio de 2009, el Congreso que presidía lo nombró presidente provisional del país. A partir del inicio de su interinato, su gobierno no fue reconocido oficialmente por ningún país del mundo, lo que muestra la percepción negativa que tuvo la comunidad internacional tanto del golpe, como la forma en la que la coalición de fuerzas conservadoras gestionó la transición (Romero).

El golpe de Estado polarizó también la opinión internacional, la cual se dividió en los bandos que protagonizaban la lucha en Tegucigalpa, San Pedro Sula y otras ciudades, donde tuvieron lugar enfrentamientos entre simpatizantes y detractores de "Mel". Visto de fuera y sin mayores pretensiones analíticas, se trataba de un conflicto que se visualizaba prima facie causado por Zelaya al proponer la consulta popular para legalizar la reelección presidencial siguiendo los pasos de Hugo Chávez. ${ }^{10}$

El análisis de esta situación permite encontrar una estrecha relación entre los intereses de la derecha y los golpistas hondureños. La lectura ideológica de las proclamas y fragmentos medulares de los discursos y alocuciones de Michelleti en la coyuntura 
del golpe evidencian claramente sus concepciones de la política y el gobierno. Con dichas intervenciones, se instituyó y presentó como portavoz de las élites, utilizando e instrumentalizando los marcos legales para la continuidad de las situaciones favorables a sus intereses (Romero).

Michelletti, después de la realización de nuevos comicios, entregó el poder a otro expresidente del Congreso Nacional, Porfirio Lobo Sosa, conocido popularmente como "Pepe". Lobo Sosa fue por entonces candidato a la presidencia del Partido Nacional (fundado en 1902) junto al empresario de origen árabe Mario Miguel Canahuati. ${ }^{12}$ En esos comicios fue derrotado por Zelaya Rosales, quien obtuvo más del 50 por ciento de los votos al final de los conteos realizados. Aunque Lobo no reconoció como ganador a su contrincante al momento de ser este proclamado ganador, aceptó el resultado emitido por las autoridades a dos semanas de presentarse el conteo final (Dalton).

La existencia de este partido en el horizonte electoral supone una variación "humanista y cristiana" de las derechas hondureñas, aspecto que se presenta muchas veces en países en los que esta orientación política es mayoritaria y hegemónica, al punto que configura las normativas y los contrapesos del poder y los procesos electorales. Esta agrupación constituye una fracción progresista de la derecha, algo más dispuesta a la pactación y al consenso que el núcleo duro liberal, heredero de la tradición oligárquica y decimonónica y, por tanto, cercana a posicionamientos populistas; obviamente, sus cuadros se alinearon a posiciones más cercanas al radicalismo de derecha después del golpe de Estado, puesto que las intenciones de Zelaya estaban claramente en su contra y era preferible cerrar filas junto a los liberales.

$\mathrm{Al}$ igual que el gobernante de transición, Lobo Sosa tenía experiencia en el puesto político anteriormente mencionado, que viene siendo "capturado" e instrumentalizado para asegurar el dominio del poder ejecutivo, configurando una dinámica singular en Centroamérica e Iberoamérica, en la que agentes políticos de los poderes económicos proceden a "copar" los puestos estratégicos de decisión política para asegurar: a) la continuidad de la hegemonía que ejercen estos y b) el control del sitial privilegiado para asegurar una perpetuación de este.

La élite política hondureña (la visible a los ojos de la población y del mundo) se evidenciaba entonces como una extensión de las élites económicas, formando un frente común y firme contra las probables oposiciones y disidencias, las cuales estaban personificadas en Zelaya y localizadas en algunos movimientos sociales que pugnan por una reforma y refundación del Estado como salida a los graves problemas de pobreza, inseguridad y carencia de perspectivas a futuro.

Pero, ante el enfoque de los analistas y cientistas, su configuración toma otro sentido pues se le analiza y comprende bajo esquemas teóricos y recursos hermenéuticos que permiten visualizar tanto el arraigo histórico de su imaginario como las proyecciones de este en la práctica política. No se trata de simples recambios inerciales generados por un principio de alternabilidad que funciona "en automático" o porque 
la voluntad de los grupos o élites políticas y económicas se imponga como parte de una "dictadura de clase". Existe, aunque no se percibe, un aspecto contractual y consensual que reproduce las relaciones de dominación y permite el juego político según las circunstancias que forman parte de dicho acuerdo. ${ }^{13}$

El golpe de Estado evidenció una ofensiva de la derecha en la que tuvo un papel especial el general Romeo Vásquez Velázquez, quien fue el autor material del apartamiento del entonces presidente constitucional del poder (Santos Villareal). Sin la participación de las fuerzas armadas, es improbable que cualquier intento golpista forjado por civiles obtuviera el triunfo y hubiera provocado el quiebre del gobierno zelayista y el exilio del jefe de Estado. ${ }^{14}$

La presidencia de Lobo Sosa evidenció, además, la continuidad de la orientación impuesta por Micheletti, caracterizándose por la persecución a los simpatizantes de Zelaya y el sostenimiento de una posición cerrada ante las reclamaciones de los movimientos sociales y sindicales, amparándose en la legitimidad obtenida en las urnas y de la cual son garantes las fuerzas de seguridad (Llanos). Esta apelación abierta a la estricta obediencia del orden constitucional, así como la dirigida al recurso de la fuerza, muestra el continuismo y la perpetuación de una práctica política excluyente que, sin embargo, es refrendada por porcentajes apreciables de las masas en los comicios realizados cada cuatro años.

Lobo Sosa, presidente de 2010 a 2014, desmontó del todo las reformas realizadas por Zelaya y reorientó el estado al rumbo que marcaba la profundización de los controles sociales por medio de la represión y violencia. Al final de su mandato, el Partido Nacional lanzó como candidato al abogado Juan Orlando Hernández (n. 1968), que también tiene en su haber la presidencia del Congreso Nacional de manera anterior a su presidencia.

Al finalizar su mandato, Hernández anunció que buscaría la reelección, para lo cual fue apoyado por dos corrientes de su partido "Juntos por más cambios" y "Unidos por la nueva Honduras", las cuales le postularían como candidato contra el expresidente entre 1990 y 1994 Rafael Leonardo Callejas. Con anterioridad, ningún presidente había buscado la posibilidad de reelegirse; justamente, esta tentativa que solamente fue sugerida con la consulta convocada por Zelaya provocó la intervención del Ejército. ${ }^{15}$

Tras imponerse al exmandatario y recibir la venia para competir en las elecciones de noviembre de 2017, resultó electo con más del 45 por ciento de los votos. El resultado de estos comicios fue impugnado abiertamente por su opositor, el docente, empresario y comunicador, omnipresente en los medios de comunicación Salvador Nasralla (n. 1953), quien había sido lanzado como candidato por un bloque denominado Alianza de Oposición contra la Dictadura y reclamaba irregularidades en el conteo de votos. No obstante las protestas y manifestaciones, muchos países reconocieron la victoria del entonces presidente (CRITERIO) (De Gori). 
El actual distanciamiento entre Juan Orlando Hernández y el gobierno norteamericano se debe a que su consolidación en el poder no dependió únicamente de la intervención directa de Estados Unidos. Otro factor determinante es la "Caravana de los Sueños" iniciada en 2018 en Honduras, que atravesó Guatemala y México, y que se ha constituido en referente de otros movimientos que contestan la política antimigratoria del actual gobierno estadounidense. En este mismo ámbito, la administración Trump no llegó a un acuerdo que permitiría a Honduras transformarse en el "Tercer País Seguro". En el contexto de estas tensiones, trascendieron noticias e información que muestran acciones criminales (vinculadas a la trata de personas) por parte de funcionarios cercanos a Hernández (Parker).

A pesar de que los reclamos de Nasralla encontraron eco en la comunidad internacional, ninguna instancia sancionó a Hernández, beneficiario de una reforma que garantizaba su reelección. En su presidencia se evidencian orientaciones populistas que pretenden sustituir los programas que ya llevaba a cabo Zelaya, y las cuales están originadas en la agudización de una crisis que se evidencia palpablemente en los testimonios de los migrantes hondureños que saltaron a la palestra en octubre de 2018, ubicando al país en un epicentro mediático inusitado, solamente con parangón al momento en que Zelaya fue apartado violentamente del poder.

\section{Conclusiones}

El golpe de Estado contra Manuel Zelaya Rosales fue perpetrado en el marco de la reacción contra un proyecto que resultó "demasiado revolucionario" en el marco del tradicionalismo y conservadurismo que históricamente ha dominado el panorama ideológico de Honduras. Su acercamiento al "Socialismo del Siglo XXI" constituyó un ingrediente ideológico adicional a la crispación y efervescencia causada en las fuerzas conservadoras por la creciente influencia del chavismo en el Caribe y Centroamérica, y la expansión del proceso bolivariano a través de programas de integración como el ALBA, Petrocaribe y Unasur. La propuesta de la cuarta urna para verificar si en la población existía un interés por promover reformas constitucionales fue "la gota que derramó el vaso" y constituyó el epicentro de la crítica hacia su gestión, la cual contaba con el apoyo de importantes segmentos de la población.

Esta intervención de los militares en la vida política del país evidencia su papel como instrumentos de la dominación oligárquico-empresarial y, aún más, su escasa evolución hacia posiciones progresistas y de acompañamiento a los procesos de cambio social. Las repetidas declaraciones de Roberto Michelletti y Romeo Vásquez acerca de que, su accionar en la remoción y sustitución del Presidente Constitucional de la República fueron motivadas por la defensa de la constitucionalidad y el Estado de Derecho son cuestionables por cuanto se dieron después de efectuar, técnicamente, una separación ilegal del mandatario. 
En el derrocamiento de Zelaya existió una manifestación de los temores ideológicos que aún mantienen las fuerzas armadas y los círculos empresariales. La compatibilidad natural e histórica sostenida entre ambos sectores, que resulta determinante en otros momentos críticos, hizo que las reformas y modificaciones constitucionales que se proponía introducir desde el poder fueran asumidas como preludio y anticipo de la imposición hegemónica de condiciones contrarias tanto a sus intereses como a sus privilegios que son, por las características del consenso que rige, irrenunciables.

El abordaje del golpe de Estado en Honduras desde disciplinas como la Historia, la Ciencia Política, la Geopolítica y la Sociología puede enriquecerse si incluye la variante mediática, la cual, lejos de ser un elemento accesorio constituye una dimensión de expresión y lucha ideológica cuyo análisis e interpretación son competencia de las Ciencias Sociales y no un "patrimonio" exclusivo de la Comunicología y la Teoría del Discurso.

De cara a la Historia reciente, el golpe perpetrado en Honduras en junio de 2009 constituye un momento de reafirmación de la derecha que se preparó para contener lo que podría ser una orientación hacia el polo bolivariano de la región centroamericano. Si Manuel Zelaya se imponía en un referéndum o consulta, Honduras hubiese profundizado su pertenencia a la órbita de influencia venezolana, consolidando la izquierda en Centroamérica como nunca antes, pues para entonces, esta opción política estuvo fortalecida en Guatemala con el gobierno de Álvaro Colom Caballeros y era gobernante en El Salvador y Nicaragua con Mauricio Funes y Daniel Ortega Saavedra.

La salida de Zelaya del poder y la derrota electoral de las opciones centristas y socialdemócratas en las elecciones de 2013 y 2017 marcan un derrotero para el reforzamiento de la derecha. Al menos para los cientistas y analistas, no puede pasar desapercibido que, una vez apartada la disidencia, el bloque en el poder se ha fortalecido y replanteado la hegemonía a partir de nuevas reformas constitucionales. El hecho de que, Juan Orlando Hernández resultara reelecto en 2017 y se planteara la continuidad del gobierno del Partido no es casual y marca, elocuentemente, un contexto en el que las fuerzas populares han de aceptar el consenso autoritario en su versión "revisitada" que ha producido los mismos resultados de antaño: pobreza, represión, muerte y desplazamientos hacia otros países en busca de mejores condiciones de vida.

\section{Notas}

1 Este presidente fue el colaborador eficaz de la CIA, el Pentágono y la embajada estadounidense en Guatemala al cobijar en territorio hondureño a quienes constituyeron el núcleo del Movimiento de Liberación Nacional (MLN) cuya incursión por la frontera oriental en junio de 1954 se hizo con el poder después de la renuncia de Jacobo Árbenz Guzmán.

2 Al constituirse en institución que garantiza y vela por la seguridad pública, tiene un mandato constitucional de velar por la seguridad y el cumplimento de la Constitución, algo que frecuentemente se invoca cuando tienen lugar los golpes de Estado. En la coyuntura del golpe 
de Estado en Honduras se puede mencionar que, Romeo Vásquez Velázquez, candidato a la presidencia en 2013, menciona reiteradamente estos aspectos en un improvisado debate con Manuel Zelaya.

Estos gobernantes fueron, sucesivamente, Humberto Suazo Córdoba (1982-1986), José Azcona Hoyo (1986-1990), Rafael Leonardo Callejas (1990-1994), Carlos Roberto Reyna Idiáquez (19941998), Carlos Roberto Flores Facusse (1998-2002) y Ricardo Maduro (2002-2006). Este conjunto de condiciones marca una conceptualización para el tipo de gobierno y de Estado que tiene lugar en tiempos modernos en Honduras, una democracia electoral (Barahona).

La actividad de Chávez no tuvo parangón con la de ningún presidente en estos aspectos. Los acuerdos que forjó y las alianzas que logró para establecer el ALBA se dirigieron a toda la cuenca caribeña, contando en Centroamérica con el seguimiento y la adhesión de los movimientos de izquierda. El anhelo de crear un bloque latinoamericano que contuviera la influencia estadounidense inspiró su proselitismo en un momento en el que los grupos conservadores estadounidenses promovieron movimientos expansionistas derivados de la persecución al terrorismo islámico después de los sucesos del 11 S (invasiones de 2001 a Afganistán y 2003 a Irak) provocando también adherencias y simpatías, así como la animadversión de una fracción del conservadurismo. Esta vocación del chavismo permitió las alianzas y acuerdos de cooperación con muchos gobiernos de izquierda que confluyeron en aquel momento en muchos países que, igualmente, reciprocaron a Chávez. Actualmente (2019), la crisis del chavismo no ha permitido la pervivencia de este esfuerzo, descontinuándose la expansión del proyecto bolivariano y la coalición de las fuerzas de izquierda en el ALBA.

Esta circunstancia predispuso a Chávez a generar una retórica confrontativa contra la administración de Bush Jr. en ambos períodos (2000-2004/2004-2008), la cual iba dirigida contra el presidente norteamericano y algunos adjuntos de consabida orientación hacia la derecha como John D. Negroponte. Un punto a resaltar de las diatribas del venezolano fue el cuestionamiento hacia la existencia y actualidad de las bases norteamericanas en la región, aspecto que hacía referencia tácita a Honduras con el protagonismo estratégico de la base de Palmerola, situada en las inmediaciones de Tegucigalpa.

Los programas sociales auspiciados por Venezuela tuvieron impacto en casi todos los países de la región. De estas medidas Nicaragua recibió grandes contribuciones materializadas en programas sociales como "Una vivienda mejor", por medio del cual el gobierno entregaba materiales de construcción a familias de bajos ingresos. En El Salvador se activó el programa de alfabetización de inspiración cubana "Yo sí puedo", mientras que en Guatemala, desde el inicio del gobierno del centroizquierdista Álvaro Colom Caballeros, ganador en los comicios recientes siendo postulado por el partido "Unidad Nacional de la Esperanza" (UNE) a través del "Consejo de Cohesión Social", inició una política de combate a la pobreza desde que tuvo lugar un ensayo en 40 municipios con situación que reclamaba atención de parte del Estado. Gradualmente, estos ensayos dieron lugar a una política asistencialista, que se expresó con programas como "Escuelas Abiertas", "Transferencias Monetarias Condicionadas", "Becas Solidarias", “Mi Familia Produce", “Mi Familia Progresa”, "Bolsas Solidarias” y "Comedores solidarios" (De León Castellanos). Honduras, después de la adhesión del gobierno de Manuel Zelaya a Petrocaribe acordó la importación de 30,000 toneladas de urea y al menos 100 tractores. El destino de los fertilizantes era aumentar la producción de maíz y frijol. 
En 2013, en vísperas de las elecciones en que triunfó Juan Orlando Hernández, un intenso debate telefónico entre el exmandatario y el entonces candidato presidencial Romeo Vásquez generado y auspiciado por una cadena televisiva y socializado en los espacios electrónicos como video dejó entrever la vinculación de la derecha y el Ejército. El análisis de este, a pesar de la improvisación y la exhibición de posiciones altamente disonantes, permite encontrar algunos puntos clave del posicionamiento de las fuerzas armadas frente a las tentativas de Zelaya por realizar la Consulta Popular para convocar o no una (Primerísima) Constituyente. A pesar de que es un video extenso, no tiene desperdicio en cuanto a posibilidades del análisis de discurso de la derecha:

La Capitanía del Reyno de Goathemala, a cuyo territorio perteneció Honduras durante el período colonial, proclamó su independencia de España a partir de la convocatoria del Marqués don Mariano de Aycinena para votar por ello el día 15 de septiembre de 1821 a una junta a la que asistieron muchos dignatarios locales, pero no voceros del sentir de las demás Provincias. Anteriormente, existía un consenso cerrado acerca de cómo tendría lugar la independencia al redactar Aycinena un "Plan Pacífico". Uno de los artículos del Acta que se redactó al alcanzarse la decisión de que tendría lugar ahí la emancipación reflejó el sentir de las élites, manifestando que tal reunión debía tomar la iniciativa para evitar que el pueblo proclamara la emancipación y conjurar las consecuencias de ello (Prieto Rozos).

9 Esta es una consideración al respecto de tomar las teorías como leyes que han de "cumplirse" a rajatabla para encontrar su validación como elementos interpretativos. A todas luces, la realidad no puede obedecer a la teoría. La construcción de los elementos teóricos, social como la de todos los elementos constitutivos de la estructura de las Ciencias Sociales o Humanas, también implica reconocer un proceso de asimilación de nuevos elementos aportados por los cientistas, así como una contrastación con escenarios distintos a los que constituyeron el contexto en el cual fueron generados. Estos problemas los acarrea la adherencia a las posturas ortodoxas, que reclaman un mismo proceder analítico e interpretativo en todos los casos, aplicando la teoría de forma mecanicista y sin efectuar las consideraciones y precisiones contextuales pertinentes.

Esta vocación a la consultoría pública sobre aspectos medulares queda expresada en el artículo 71 de la Constitución de la República Bolivariana de Venezuela, al establecer que "las materias de especial trascendencia nacional serán sometidas a referendo consultivo por iniciativa del Presidente o Presidenta de la República en Consejo de Ministros" (Constitución Política de la República Bolivariana de Venezuela 1999). Como está visto, el modelo bolivariano de Chávez procuraba involucrar a las mayorías en los asuntos de decisión pública bajo un marco de consulta, lo que no es de dudar, fue emulado por Manuel Zelaya con la polémica "cuarta urna".

11 La defensa de la Constitución vigente fue uno de los principales argumentos de los voceros del Ejército hondureño en la coyuntura golpista, según lo muestran las alocuciones de Romeo Vásquez, estas fueron difundidas tanto por medios televisivos, escritos, radiales como por el internet. Sin mucho esfuerzo, puede afirmarse que, en algunos sitios web especializados en videos, se puede obtener una compilación de los mismos la cual puede ayudar a establecer un testimonial del pensamiento político de la derecha hondureña, que con su proceder recalcitrante y represor, viene superando en lo que va del siglo XXI a los pares que gobiernan los países vecinos. 
Esta minoría étnica tiene gran importancia dentro de las esferas comercial y económica de Honduras. La gran mayoría de sus integrantes descienden de algunas oleadas de migrantes del Medio Oriente a finales del siglo XIX y han tenido una inserción exitosa como intermediarios desde entonces. Desde hace algún tiempo incursionan en la política como diputados y dirigentes partidistas.

Parte de la cultura política de muchos segmentos poblacionales apunta a concebir lo político como una dimensión fuera de la realidad, haciéndolo un elemento quasi metafísico que no tiene vinculación con la vida social. Además de que esto significa la pervivencia del analfabetismo político, constituye una forma de pensamiento que asoma fácilmente cuando no se comprende la existencia de un pacto como elemento fundacional de la estructura social.

En la ofensiva militar contra Zelaya se encuentran muchas evidencias de que la derecha apela también a recursos populistas cuando trata de atacar la retórica o las acciones de los gobiernos que, de una forma u otra, plantean una oposición a la continuidad del modelo que reproduce los intereses y privilegios de la burguesía comercial o las oligarquías terratenientes. La "defensa de la constitución", del "orden público" y demás argumentos para justificar los golpes de Estado forman parte de un imaginario y de una estrategia de lucha definida que tiene su resonancia en las masas, más aún cuando se integra a las mismas al "bloque" que se enfrenta a las disidencias que "perturban el orden". Esta apelación a la Constitución no puede tenerse como simple recurso retórico, debe analizarse más a fondo, debido a que constituye una de las fórmulas de convocatoria mediática de la derecha que puede reproducirse y reeditarse en algún momento.

Esta es una muestra evidente de la ambivalencia de las fuerzas armadas y su integración al campo de intereses de la derecha. La reelección que Zelaya proponía con la "urna de la discordia" en la Consulta Popular de junio de 2009 fue interpretada como violatoria a la Constitución y ahora, una vez apartado del poder y cortada la posibilidad de incidencia de quienes apoyaron al zelayismo, Hernández hizo uso de las reformas constitucionales para reelegirse y perpetuar a la derecha.

\section{Bibliografía}

Acanda González, J. L. Traducir a Gramsci. La Habana: Editorial de Ciencias Sociales, 2007.

Alins Vanderbliet, S. El proyecto regional bolivariano y las consecuencias de la muerte de Hugo Chávez. Agenda Internacional. Lima: Pontificia Universidad del Perú, 2013.

Arévalo Bermejo, J. J. Escritos complementarios. Guatemala: Editorial José de Pineda Ibarra, 1988. Argueta, J., Cruz Alas, J. y Sellingson, M. Cultura política de la democracia en Honduras. San Salvador: Imprenta Criterio, 2007.

Barahona, M. Estado oligárquico, crisis y corrupción política. El golpe de Estado en Honduras desde la perspectiva de los derechos humanos. Fernández Víctor y Mejía A. Joaquín, (Coords.). San Pedro Sula: Casa San Ignacio, 2010.

Barrios Oviedo, A. Centroamérica en la geopolítica desbordada del Norte y del Sur. Centroamérica casa común e integración regional. Soto Acosta, W. y Suárez Ulloa, M. (Eds.). San José: Universidad de Costa Rica, 2014. 197-222.

Boersner, Demetrio. Gobiernos de izquierda en América Latina: tendencias y experiencias. Nueva Sociedad 197(2007): 100-113. 
Bográn, A. (27 de enero de 2007). Yo si puedo expande su lucha contra el analfabetismo. Diario La Prensa.

Constitución Política de la República Bolivariana de Venezuela 1999. Caracas (2000): Servicio de Preprensa-Imprenta Nacional.

CRITERIO. (26 de diciembre de 2017). Conozca los países que reconocen la reelección de Hernández pese al fraude.

Dalton, J. J. (12 de agosto de 2005). El liberal Manuel Zelaya virtual presidente electo de Honduras. Diario El País.

De Gori, E. y Villacorta Zuloaga, C. E. Golpe electoral y crisis politica en Honduras. Buenos Aires: CLACSO, 2018.

De León Castellanos, L. M. El discurso político sobre la pobreza en Guatemala: El caso del Partido Unidad Nacional de la Esperanza (UNE), durante los años 2005-2008. Guatemala: Escuela de Ciencia Política USAC, 2018.

Hoenecke, H. Pretorianismo, legitimidad y opinión pública. Nueva Sociedad, (1986): 69-76.

Llanos, M. y Maistrentedet, L. Ruptura y continuidad: La caída de "Mel Zelaya" en una perspectiva comparada. América Latina hoy, 55. Salamanca (2010): 173-197.

Lozano, W. La izquierda latinoamericana en el poder. Nueva Sociedad 197, (2017): 127-146.

Modonessi, M. Subalternidad, antagonismo, autonomía. Marxismo y subjetivación política. Buenos Aires: Prometeo CLACSO Facultad de Filosofía y Letras Universidad de Buenos Aires, 2010.

Parker, A. Lista de EE. UU. destaca nexos criminales de presidentes del Triángulo Norte. InSight Crime.

Pérez, C. Ciencias Sociales y realidad social en Centroamérica. Revista de la Cepal, (2010): 147:162.

Petkoff, T. Las dos izquierdas. Nueva Sociedad 197, (2007): 114-128.

Petras, J. Imperialismo y Barbarie. Xalaparta, Navarra, 2011.

Prieto Rozos, A. Historia integra de América Latina. Guatemala): Escuela de Ciencia Política USAC, 2016.

Radio “La primerísima”. Honduras importará fertilizantes por Petrocaribe, 2008.

Ribeiro, D. El pueblo brasileño la formación y el sentido de Brasil. Sao Paulo: Letras Compartilhas, 1995.

Rojas Bolaños, M. La Política. Historia General de Centroamérica vol. 5. Edelberto Torres Rivas (Coord.). Madrid (1993): 85-163. Sociedad estatal Quinto Centenario.

Romero, R. Honduras la difícil opción democrática. Buenos Aires: CLACSO, 2014.

Santos Villareal, G. Crisis política en Honduras I (21 de junio a 8 de julio de 2009). Seguimiento a crisis política en Honduras. México: Centro de Documentación, Información y Análisis, 2009.

Tecnotvhn. Youtube. Mayo de 2013. Mel Zelaya pone en su lugar al General Golpista Romeo Vásquez Velázquez.

Torres Rivas, E. Centroamérica entre revoluciones y democracia. Buenos Aires: CLACSO, 2014.

Valencia, J. Chávez/chavista, contraseña cómplice... por aquí pasó, compadre. Chavismo, genealogía de una pasión política. Vargas, Iraida (Comp.). CLACSO, 2017. 31-47.

Vilas, C. M. La izquierda latinoamericana y el surgimiento de los regímenes nacional-populares. Nueva Sociedad, 197, (2017): 84-99. 
Néstor Véliz Catalán. Guatemalteco. Alumno Licenciatura para la Enseñanza de la Historia USAC, PEM en Historia y Ciencias Sociales (2006). Pensum cerrado Licenciatura en Historia (2009). Se desempeña como docente en el área de Ciencias Sociales y es investigador independiente en Historia Política de Guatemala y Centroamérica y Actualidad Mundial.

Contacto: nestorveliz774@gmail.com

ORCID: 0000-0003-1940-290X 